\title{
Knowledge, attitude, practice, and toxicity symptoms associated with pesticide use among farm workers in the Gaza Strip
}

\author{
M M Yassin, T A Abu Mourad, J M Safi
}

See end of article for

authors' affiliations

Occup Environ Med 2002;59:387-394

Correspondence to: Prof J M Safi, Environmental Protection and Research Institute, EPRI-Gaza, Palestine, PO Box 1175, Gaza, Palestinian National Authority; eprigaza@palnet.com

Accepted

12 February 2002

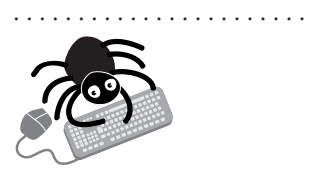

The questionnaire can be viewed on the OEM website
Aims: To assess knowledge, attitude, practice, and toxicity symptoms associated with pesticide use and exposure among 189 farm workers in the Gaza Strip.

Methods: A cross section of agricultural farm workers in the Gaza Strip were asked to fill in a questionnaire on knowledge, attitudes, practice towards pesticide use, and associated toxicity symptoms. Results: Farm workers reported high levels of knowledge on the health impact of pesticides (97.9\%). Moderate to high levels of knowledge were recorded on toxicity symptoms related to pesticides. Most farm workers were aware of the protective measures to be used during applying pesticides. However, no one took precautions unless they knew about the measures. Burning sensation in eyes/face was the commonest symptom (64.3\%). The prevalence of self reported toxicity symptoms was dependent on mixing and use of high concentrations of pesticides. The highest percentage of self reported toxicity symptoms was found among the farm workers who returned to sprayed fields within one hour of applying pesticides.

Conclusions: Farm workers in the Gaza Strip used pesticides extensively. Despite their knowledge about the adverse health impact of the pesticides, the use of protective measures was poor. Most had self reported toxicity symptoms, particularly the younger workers. It would be useful to minimise the use of pesticides and encourage alternative measures. Prevention and intervention programmes regarding the use of protective measures and monitoring the health status of farm workers should be implemented.
$\mathrm{T}$ he Gaza Strip is an elongated area located in a semi-arid region. It is bordered by Egypt from the south, the Negev Desert from the east, and the Mediterranean Sea from the west. The total surface area of the Gaza Strip is $365 \mathrm{~km}^{2}$ and its population is estimated to be more than one million people. ${ }^{1}$ The main crops grown include citrus fruits, olives, almonds, grapes, other subtropical fruits, vegetables, and flowers. ${ }^{2}$ More than 250 metric tons of formulated pesticides, mainly insecticides and fungicides, in addition to one thousand metric tons of methyl bromide, are used annually in the Gaza Strip. Some of these pesticides have been internationally suspended, banned, or cancelled because of their mutagenicity, teratogenicity, or carcinogenicity. ${ }^{3-5}$ Under the Montreal Protocol methyl bromide is considered to be an ozone depleting substance; it will be phased out in 2005 for industrialised countries and in 2015 for developing countries. ${ }^{6}$

Several cases of chronic toxicity or death have been reported and proven among farm workers exposed to different types of pesticides in the Gaza Strip and other developing countries. This may be a result of the use or misuse of these highly toxic compounds, where precautions regarding wearing protective gear during handling and application are poorly followed. $.^{2-5} 7-10$ However, the use of pesticides is unavoidable, particularly in a very densely populated area with low income such as the Gaza Strip.

The main aim of the present study was to assess knowledge, attitude, and practice towards pesticides, and self reported toxicity symptoms related to pesticide exposure among farm workers applying pesticides in the Gaza Strip with the following specific objectives:

(1) Assessment of the knowledge of farm workers regarding pesticide effects, their route of entry into the body, self reported toxicity symptoms, and the use of protective gear as well as determination of their attitude towards pesticides.

(2) Evaluation of work practices regarding the use of protective measures and activities with potential for exposure to pesticides.

(3) Identification of self reported toxicity symptoms associated with pesticide exposure and their relation to work practices.

\section{SUBJECTS AND METHODS}

The investigation was a cross sectional study. The target population was agricultural farm workers in the Gaza Strip working in open or closed fields, or both, and applying pesticides during the summer of 1999.

The estimated number of agricultural farmers using pesticides in the Gaza Strip was 9 out of 10 (personal communication with Ministry of Agriculture, Palestinian National Authority). The sample size was determined in order to have 95\% confidence limits of 5\% maximum error of the estimate, when the prevalence is $90 \% .{ }^{11}$ This leads to a requirement of 138 farm workers. For a no-response expectation, the sample size was increased to 200 farm workers.

A stratified sample was used; the Gaza Strip was divided geographically into five Governorates: Northern, Gaza, Mid Zone, Knan Younis, and Rafah. The Palestinian Ministry of Agriculture estimated the number of agricultural farmers as 15000 in Gaza Governorates, distributed as follows: Northern (3000), Gaza (2000), Mid Zone (3000), Khan Younis (4500), and Rafah (2500). Therefore, the sample size of 200 farm workers was distributed according the number of farmers in each Governorate as follows: Northern (40), Gaza (27), Mid Zone (40), Khan Younis (60), and Rafah (33). 
Table 1 The response of farm workers $(n=200)$ selected from different Governorates of the Gaza Strip

\begin{tabular}{lccr}
\hline & \multicolumn{2}{l}{ Farm workers } \\
\cline { 2 - 4 } Governorate & Sample size & $\begin{array}{l}\text { No. of } \\
\text { respondents }\end{array}$ & $\%$ \\
\hline Northern & 40 & 38 & 95.0 \\
Gaza & 27 & 26 & 96.3 \\
Mid Zone & 40 & 40 & 100.0 \\
Khan Younis & 60 & 56 & 93.3 \\
Rafah & 33 & 29 & 87.9 \\
Total response & 200 & 189 & 94.5 \\
\hline
\end{tabular}

A meeting interview was used for filling in the questionnaire. All interviews were conducted face to face by one investigator who had a Masters degree of public health and is familiar with farm workers. ${ }^{12}$ The questionnaire was based on United States Environmental Protection Agency questions, and on that used in a similar study with few modifications. ${ }^{13}{ }^{14}$ Most questions were one of two types: the yes/no question, which offers a dichotomous choice; and the multiple choice question, which offers several fixed alternatives. ${ }^{15}$ A questionnaire was piloted with 10 farm workers not included in the sample from the study area, and modified as necessary.

The questionnaire included questions related to: background information, for example, area, age, education, and marital status; the health impact of exposure to pesticides (self reported toxicity symptoms associated with pesticides use); knowledge of the acute and chronic toxicity of pesticides, prohibited pesticides, effect of pesticides on human health, other alternatives to pesticides, the route of pesticide entry into the human body, and names of pesticides used; and attitudes regarding the use of pesticides and protective equipment or clothes during preparation and application of pesticides. Practice questions included: the wearing of protective clothes; following label instructions and agronomist guiding; re-entry period in the farm after applying pesticides; smoking, eating, drinking water, or chewing gum during application of pesticides; whether to have a water bath or not after application; and whether they complied with the safety period and concentration recommended, either by the agronomist or by the pesticide label. The sample of 200 subjects was selected randomly from different locations in each subarea. The farm workers who did not meet the criterion of being involved in applying pesticides during the summer of 1999, were excluded and replaced by those who did meet the criteria.

Data were analysed by computer using the SPSS/PC ( Statistical Package for the Social Sciences Inc., Chicago, Illinois) and EPIINFO (Epidemiological Program Office, CDC, Atlanta, Georgia) statistical packages. Simple distribution of the study variables, the cross tabulation, and normal $\chi^{2}$ tests were applied. Yates's continuity correction test, $\chi^{2}$ (corrected) , was used when not more than $20 \%$ of the cells had an expected frequency of less than five and when the expected numbers were small. The $\chi^{2}$ test for trend, $\chi^{2}$ (trend) with $1 \mathrm{df}$, which is a more sensitive test that looks for an increasing (or decreasing) trend in the proportions over the columns having natural order, was used. ${ }^{16}{ }^{17}$ These tests were used to identify the significance of the relations, associations, and interactions among knowledge, attitude, practice towards pesticides, and the prevalence of self reported toxicity symptoms.

\section{RESULTS}

The total response for the questionnaire interview was $94.5 \%$ $(\mathrm{n}=189)$. Table 1 shows that the highest response among the farm workers was found in the Mid Zone Governorate (100\%, $\mathrm{n}=40$ ) and the lowest response in Rafah Governorate $(87.9 \%, n=29)$. The average age of the respondent farm workers $(n=189)$ was $32.4(0.8)$ years old.

Analysis of the educational status of the respondent farm workers $(\mathrm{n}=189)$ showed that $25(13.2 \%)$ had a university degree, 81 (42.9\%) had finished secondary school, $42(22.2 \%)$ had finished preparatory school, 25 (13.2\%) had passed primary school, and $16(8.5 \%)$ were illiterate. A total of 139 $(73.5 \%)$ were married; only seven $(5.0 \%)$ had no children. In addition, 64 (33.9\%) were smokers.

The questions related to the type of agricultural field and planted crops illustrated that $109(57.7 \%)$ were growing their crops in both open and closed fields, $59(31.2 \%)$ were growing their crops in open fields, and $21(11.1 \%)$ were growing their crops in closed fields. Vegetables was the crop grown by most farm workers $(n=173,91.5 \%)$, followed by fruits $(n=57$,

Table 2 Knowledge of the respondent farm workers regarding name, health effects, biological and natural controls, route of pesticide entry into body, and fate of pesticide residues

\begin{tabular}{|c|c|c|c|}
\hline \multirow[b]{2}{*}{ Items } & \multicolumn{3}{|c|}{ Farm workers with knowledge } \\
\hline & Sample size & Frequency & $\%$ \\
\hline \multicolumn{4}{|l|}{ Name of the pesticides used } \\
\hline Knowing the name of pesticides used & 189 & 183 & 96.8 \\
\hline \multicolumn{4}{|l|}{ Health effect of pesticides } \\
\hline $\begin{array}{l}\text { Knowing the adverse health effects of pesticide } \\
\text { exposure on human health }\end{array}$ & 189 & 185 & 97.9 \\
\hline $\begin{array}{l}\text { Knowing not all pesticides have the same adverse } \\
\text { health effects }\end{array}$ & 185 & 155 & 83.8 \\
\hline \multicolumn{4}{|l|}{ Biological and natural control } \\
\hline Knowing biological control & 189 & 23 & 12.2 \\
\hline Knowing natural control & 189 & 36 & 19.0 \\
\hline \multicolumn{4}{|l|}{ Route of pesticide entry into body } \\
\hline Inhalation (nose) & 189 & 176 & 93.1 \\
\hline Skin & 189 & 167 & 88.4 \\
\hline Mouth & 189 & 166 & 87.8 \\
\hline \multicolumn{4}{|l|}{ Fate of pesticide residues } \\
\hline Air & 189 & 113 & 59.8 \\
\hline Soil & 189 & 126 & 66.7 \\
\hline Groundwater & 189 & 80 & 42.3 \\
\hline Leaves and fruits of vegetables and fruits & 189 & 103 & 54.5 \\
\hline
\end{tabular}


Table 3 Knowledge of toxicity symptoms among farm workers $(n=185)$ * in the Gaza Strip

\begin{tabular}{lc}
\hline Symptoms & $\begin{array}{l}\text { Farm workers with } \\
\text { knowledge of toxicity } \\
\text { symptoms } \\
\text { No. (\%) }\end{array}$ \\
\hline Headache & $153(82.7)$ \\
Burning sensation in eyes/face & $177(95.7)$ \\
Weakness & $128(69.2)$ \\
Fever & $106(57.3)$ \\
Watering eyes & $163(88.1)$ \\
Skin rash & $127(68.6)$ \\
Itching and skin irritation & $157(84.9)$ \\
Dizziness & $152(82.2)$ \\
Cold/breathlessness/chest pain & $158(85.4)$ \\
Forgetfulness & $49(26.5)$ \\
Loss of libido & $52(28.1)$ \\
Salivation and vomiting & $141(76.2)$ \\
Abdominal pain/diarrhoea & $134(72.4)$ \\
\hline *Only 185 farm workers, who did know the adverse health effects of \\
pesticides, were questioned.
\end{tabular}

$30.2 \%)$, citrus fruits $(\mathrm{n}=30,15.9 \%)$, and flowers $(\mathrm{n}=12$, $6.3 \%)$. In addition, 65 (34.4\%) farm workers reported that the agronomists were visiting their farms periodically. Those agronomists came from the Ministry of Agriculture and the Palestinian Agricultural Relief Committee.

\section{Knowledge of farm workers about pesticides}

Table 2 illustrates the knowledge of the respondent farm workers $(n=189)$ regarding the name, health effects, biological and natural controls, route of pesticide entry into the body, and the fate of pesticide residues. A total of 185 $(97.9 \%)$ farm workers had knowledge about the adverse health effects of pesticides on human health. When those farm workers were questioned further about the degree of health impact of pesticides, a total of 155 (83.8\%) knew that not all pesticides have the same adverse health effects. It was also found that $183(96.8 \%)$ knew the name of the pesticides they were using. A total of 23 (12.2\%) and 36 (19.0\%), respectively, knew biological and natural control as alternatives to pesticides for pest control. Table 2 also presents the possible routes of exposure to pesticides known by the respondent farm workers; 176 (93.1\%) farm workers claimed that inhalation is the route of entry, followed by 167 (88.4\%) who reported that skin is the route of entry, and $166(87.8 \%)$ who claimed that the mouth is the route of entry of pesticides into the body. In terms of knowledge regarding the fate of pesticide residues, the highest number $(\mathrm{n}=126,66.7 \%)$ reported that pesticide residues may be detected in the soil, whereas the lowest frequency ( $\mathrm{n}=80,42.3 \%$ ) reported that pesticide residues may be detected in the groundwater.

Table 3 shows that the toxicity symptoms best known were a burning sensation in the eyes/face $(\mathrm{n}=177,95.7 \%)$, watering eyes $(\mathrm{n}=163,88.1 \%)$, cold/breathlessness/chest pain $(\mathrm{n}=158,85.4 \%)$, itching and skin irritation $(\mathrm{n}=157,84.9 \%)$, headache $(\mathrm{n}=153,82.7 \%)$, and dizziness ( $\mathrm{n}=152,82.2 \%)$. The toxicity symptoms least known were loss of libido $(\mathrm{n}=52,28.1 \%)$ and forgetfulness $(\mathrm{n}=49,26.5 \%)$.

Table 4 illustrates the knowledge of farm workers $(n=185)$ about protective gear. A total of 167 (90.3\%) farm workers had information that gloves can protect skin of the hands from the adverse health effects of pesticides, while a total of 163 $(88.1 \%)$ reported that goggles can protect the eyes from the adverse effects of pesticides. A total of 169 (91.4\%) believed that wearing a wide brimmed hat and special boots can protect the head and feet from pesticides. A total of 180 $(97.3 \%)$ admitted that wearing an oral-nasal mask can prevent entrance of the pesticide drifts through the mouth or nose into the human body. A total of 177 (95.7\%) reported that wearing protective gear as overalls can protect the whole body. The interaction between use of protective measures and awareness of farm workers towards these measures showed that most farm workers were aware of the protective measures to be used during application of pesticides, but no one took precautions unless they knew about the measures.

\section{Attitudes of farm workers towards pesticides}

A total of $112(59.3 \%)$ farm workers $(n=189)$ were against the use of pesticides for pest control. They justified the use of pesticides by the absence of other successful alternatives for pest control. On the other hand, a total of $77(40.7 \%)$ reported that use of pesticides is the best and most efficient way for pest control.

In term of body resistance to pesticides, a total of 125 $(67.6 \%)$ farm workers $(n=185)$ believed that their body has developed resistance to pesticides, whereas $60(32.4 \%)$ had the opposite opinion.

\begin{tabular}{|c|c|c|c|}
\hline Protective measures in use & $\begin{array}{l}\text { Have knowledge } \\
\text { No. (\%) }\end{array}$ & $\begin{array}{l}\text { Have no knowledge } \\
\text { No. (\%) }\end{array}$ & $\mathrm{p}$ valuet \\
\hline \multicolumn{4}{|l|}{ Wear gloves $(n=167)$} \\
\hline Yes & $37(22.2)$ & $0(0.0)$ & \multirow[t]{2}{*}{0.06} \\
\hline No & $130(77.8)$ & $18(100)$ & \\
\hline \multicolumn{4}{|l|}{ Wear goggles $(n=163)$} \\
\hline Yes & $15(9.2)$ & $0(0.0)$ & \multirow{2}{*}{0.28} \\
\hline No & $148(90.8)$ & $22(100)$ & \\
\hline \multicolumn{4}{|c|}{ Wear wide brimmed hat $(n=169)$} \\
\hline Yes & $23(13.6)$ & $0(0.0)$ & \multirow[t]{2}{*}{0.24} \\
\hline No & $146(86.4)$ & $16(100)$ & \\
\hline \multicolumn{4}{|l|}{ Wear oral-nasal mask $(n=180)$} \\
\hline Yes & $41(22.8)$ & $0(0.0)$ & \multirow{2}{*}{0.50} \\
\hline No & $139(77.2)$ & $5(100)$ & \\
\hline \multicolumn{4}{|l|}{ Wear special boots $(n=169)$} \\
\hline Yes & $28(16.6)$ & $0(0.0)$ & \multirow{2}{*}{0.16} \\
\hline No & $141(83.4)$ & $16(100)$ & \\
\hline \multicolumn{4}{|l|}{ Wear overalls $(n=177)$} \\
\hline Yes & $35(19.8)$ & $0(0.0)$ & \multirow[t]{2}{*}{0.40} \\
\hline No & $142(80.2)$ & $8(100)$ & \\
\hline
\end{tabular}


Table 5 Pesticides known by farm workers $(n=183)^{*}$ as "frequently used" during summer season (1999) in the Gaza Strip

\begin{tabular}{lc} 
& $\begin{array}{l}\text { Farm workers who } \\
\text { reported use of pesticides }\end{array}$ \\
Agricultural pesticides & No. (\%) \\
\hline Insecticides & \\
Organophosphorus & $109(59.6)$ \\
Methamidophos & $75(41.0)$ \\
Chlorpyrifos & $20(10.9)$ \\
Fenamiphos & $16(8.7)$ \\
Dimethoote & $6(3.3)$ \\
Dichlorovos & $3(1.6)$ \\
Oxydemetonmethyl & $2(1.1)$ \\
Azinophosmethyl & $44(24.0)$ \\
Carbamate & $19(10.4)$ \\
Methomyl & $74(40.4)$ \\
Carbosulphan & $61(33.3)$ \\
Pyrethroids & $9(4.9)$ \\
Cypermethrin & \\
Fenpropathrin & $86(47.0)$ \\
Cyhalothrin & $37(20.2)$ \\
Organochlorine & $30(16.4)$ \\
Endosulphan & $28(15.3)$ \\
Other groups & $21(11.5)$ \\
Abamectin & $6(3.3)$ \\
Thiocalm hydrogen oxalate & $116(63.4)$ \\
Imidaclopride & $41(22.4)$ \\
Chlorfluazuron & $27(14.8)$ \\
Bromopyalate & $23(12.6)$ \\
Fungicides & $19(10.4)$ \\
Mancozeb & $15(8.2)$ \\
Penconazole & $10(5.5)$ \\
Triadimenol & $8(4.4)$ \\
Maneb & $7(3.8)$ \\
Propineb & $6(3.3)$ \\
Copper oxychloride & $6(3.3)$ \\
Benomyl & $12(6.6)$ \\
Propamocarb HCl & $18(9.8)$ \\
Chlorothalonil chlorotaluran & \\
Pyrazophos & \\
Captan & \\
Fumigants & \\
Methyl bromide & \\
Other pesticides $\dagger$ & \\
\hline *Only 183 farm workers, who did know the names of pesticides they \\
used, were questioned. \\
†Other pesticides: clofentenine, pirimicarb, fenazaquin, ametraz, \\
cyfluthrin, methalaxyle, fenarimol, glyphosate, and bifenthrin. \\
\hline
\end{tabular}

\section{Practices towards pesticides}

All interviewed farm workers $(n=189)$ used pesticides; 183 knew the name of the pesticides they used. Table 5 lists the types and names of pesticides that were frequently used during the summer of 1999 in the Gaza Strip. The most common insecticides were organophosphates, carbamates, pyrethroids, and organochlorines. Other types of agricultural pesticides used included fungicides and fumigants.

The distribution of organophosphorus insecticide use was as follows: Northern $(\mathrm{n}=27,71.1 \%)$, Gaza $(\mathrm{n}=24,92.3 \%)$, Mid Zone $(\mathrm{n}=33,82.5 \%)$, Khan Younis $(\mathrm{n}=41,73.2 \%)$, and Rafah ( $\mathrm{n}=19,65.5 \%)$

Table 6 shows that 149 (78.8\%) farm workers stored pesticide containers on the farm, whereas $34(18.0 \%)$ stored them in the home. In addition, $122(64.6 \%)$ threw the empty pesticide containers on the garbage site or along the street, while 85 $(45.0 \%)$ buried or burned them.

Table 7 lists the different protective measures regularly used by farm workers $(n=189)$ during application of pesticides. The highest number $(\mathrm{n}=41,21.7 \%)$ wore oral-nasal masks and the lowest number $(\mathrm{n}=15,7.9 \%)$ wore goggles during preparation and application of pesticides. The numbers of farm workers who mentioned not drinking, not eating, not smoking, and not chewing gum during application of pesticides were 131 (69.3\%), $154(81.5 \%), 168(88.9 \%)$, and
Table 6 Storage of pesticides and fate of empty containers as reported by farm workers $(n=189)$

\begin{tabular}{lc}
\hline Variable & $\begin{array}{c}\text { Farm workers } \\
\text { No. (\%) }\end{array}$ \\
\hline $\begin{array}{l}\text { Storage of pesticides } \\
\text { On the farm site }\end{array}$ & $149(78.8)$ \\
In the home & $34(18.0)$ \\
Fate of empty containers & $0(0.0)$ \\
Home use & $2(1.1)$ \\
Storage of other pesticides & $122(64.6)$ \\
Throw on garbage site or along the street & $85(45.0)$ \\
Burying or burning & \\
\hline
\end{tabular}

Table 7 Farm workers $(n=189)$ who reported almost always using protective measures during application of pesticides

\begin{tabular}{ll} 
Protective measures in use & $\begin{array}{l}\text { Farm workers } \\
\text { No. (\%) }\end{array}$ \\
\hline Wear gloves & $37(19.6)$ \\
Wear goggles & $15(7.9)$ \\
Wear wide brimmed hat & $23(12.2)$ \\
Wear oral-nasal mask & $41(21.7)$ \\
Wear special boots & $28(14.8)$ \\
Wear overalls & $36(19.0)$ \\
Have water bath after application & $102(54.0)$ \\
Not smoking during application & $168(88.9)$ \\
Not eating during application & $154(81.5)$ \\
Not drinking during application & $131(69.3)$ \\
Not chewing gum during application & $183(96.8)$ \\
\hline
\end{tabular}

$183(96.8 \%)$, respectively. Moreover, 102 (54.0\%) had a water bath directly after applying pesticides.

The activities of farm workers $(n=189)$ with potential for exposure to pesticides showed that a total of $106(56.1 \%)$ used the recommended concentration of pesticides; only two (1.1\%) did not use specific concentrations. A total of 81 $(42.9 \%)$ used more than the recommended concentration, but none used less than the recommended concentration. A total of $170(89.9 \%)$ reported that they mixed two or more pesticides before they applied them. Regarding the re-entry period, two farm workers gave no response, 107 (57.2\%) re-entered the field within an hour, 63 (33.7\%) re-entered during 2-12 hours, and 17 (9.1\%) re-entered more than 12 hours after applying pesticides.

Eight farm workers (4.2\%) kept first aid equipment, and 29 $(15.3 \%)$ participated in seminars, training, and other activities related to the hazards of pesticides and their effects on human health. Organisations which conducted these seminars included the Environmental Protection and Research Institute, the Palestinian Agricultural Relief Committee, and the Ministry of Agriculture.

\section{Prevalence of self reported toxicity symptoms related to pesticides}

A total of 185 farm workers, who knew the adverse health effects of pesticides, were questioned about toxicity symptoms. The recall period was shortened to three months preceding the interview to minimise the possibility of recall bias. Table 8 lists the prevalence of self reported toxicity symptoms. A total of $154(83.2 \%)$ had self reported toxicity symptoms related to pesticides, with burning sensation in the eyes/ face being the most common $(\mathrm{n}=119,64.3 \%)$ and forgetfulness the least common $(\mathrm{n}=3,1.6 \%)$. However, several cases of poisoning and death associated with pesticide use were recalled by the interviewed farm workers. A total of 
Table 8 Prevalence of self reported toxicity symptoms among farm workers $(n=185)^{*}$ in the Gaza Strip

\begin{tabular}{lc}
\hline & $\begin{array}{l}\text { Prevalence of self reported } \\
\text { toxicity symptoms experienced } \\
\text { in the past 3 months } \\
\text { No. (\%) }\end{array}$ \\
Symptoms & $49(26.5)$ \\
\hline Headache & $119(64.3)$ \\
Burning sensation in eyes/face & $10(5.4)$ \\
Weakness & $6(3.2)$ \\
Fever & $35(18.9)$ \\
Watering eyes & $32(17.3)$ \\
Skin rash & $50(27.0)$ \\
Itching and skin irritation & $60(32.4)$ \\
Dizziness & $52(28.1)$ \\
Cold/breathlessness/chest pain & $3(1.6)$ \\
Forgetfulness & $5(2.7)$ \\
Loss of libido & $16(8.6)$ \\
Salivation and vomiting & $18(9.7)$ \\
Abdominal pain/diarrhoea &
\end{tabular}

*Only 185 farm workers, who did know the adverse health effects of pesticides, were questioned.

Table 9 Prevalence of self reported toxicity symptoms among farm works by locality, type of agricultural field, age, and years of using pesticides

\begin{tabular}{ll} 
Variable & $\begin{array}{l}\text { Reported toxicity } \\
\text { symptoms } \\
\text { No. (\%) }\end{array}$ \\
\hline Governorate* & \\
Northern $(n=38)$ & $31(81.6)$ \\
Gaza $(n=26)$ & $24(92.3)$ \\
Mid Zone $(n=40)$ & $29(72.5)$ \\
Khan Younis $(n=53)$ & $45(84.9)$ \\
Rafah $(n=28)$ & $25(89.3)$ \\
Type of agricultural field $\dagger$ & $18(90.0)$ \\
Closed field $(n=20)$ & $46(78.0)$ \\
Open field $(n=59)$ & $90(84.9)$ \\
Open and closed field $(n=106)$ & $56(87.5)$ \\
Age group $\neq$ & $52(86.7)$ \\
$<25(n=64)$ & $46(75.4)$ \\
$26-36(n=60)$ & $84(81.6)$ \\
$>37(n=61)$ & $48(82.8)$ \\
Years of using pesticides $\S$ & $22(91.7)$ \\
$<10(n=103)$ & \\
$11-20(n=58)$ & \\
$>21(n=24)$ & \\
\hline *Prevalence of self reported toxicity symptoms $v$ area $\left(\chi^{2}=5.75\right.$, \\
$p=0.22)$.
\end{tabular}

$58(31.4 \%)$ recalled deaths and $129(69.7 \%)$ recalled poisoning cases in the Palestinian community in the three years preceding the interview. Moreover, all farm workers $(n=189)$ reported that there were neither medical nor health care centres which provided medical services or cared for farm workers' health.

Table 9 shows the prevalence of self reported toxicity symptoms among the farm workers. The variation in the prevalence of self reported toxicity symptoms by locality was not significant $\left(\chi^{2}=5.75, p=0.22\right)$. The prevalence of self reported toxicity symptoms was higher among farm workers who work in closed agricultural fields $(90.0 \%)$ than in those who work in open ones $(78.0 \%)$. Furthermore, the variation in the prevalence of self reported toxicity symptoms by type of agricultural field was not significant $\left(\chi^{2}=2.04, \mathrm{p}=0.36\right)$.
Table 10 Prevalence of self reported toxicity symptoms among farm workers by pesticide concentration applied, mixing of pesticides, and re-entry period

\begin{tabular}{|c|c|}
\hline Variable & $\begin{array}{l}\text { Prevalence of self } \\
\text { reported toxicity } \\
\text { symptoms } \\
\text { No. (\%) }\end{array}$ \\
\hline \multicolumn{2}{|l|}{ Pesticide concentration applied* } \\
\hline Less than recommended $(n=2)$ & $1(50.0)$ \\
\hline Recommended $(n=103)$ & $80(77.7)$ \\
\hline More than recommended $(n=80)$ & 73 (91.3) \\
\hline \multicolumn{2}{|l|}{ Mixing pesticides $†$} \\
\hline Mixing two or more pesticides $(n=168)$ & $144(85.7)$ \\
\hline Not mixing two or more pesticides $(n=17)$ & $10(58.8)$ \\
\hline \multicolumn{2}{|l|}{ Re-entry period (hours) $\ddagger$} \\
\hline $0-1(n=105)$ & $90(85.7)$ \\
\hline $2-12(n=61)$ & $50(82.0)$ \\
\hline $13-24(n=17)$ & $14(82.4)$ \\
\hline Non-response $(n=2)$ & - \\
\hline \multicolumn{2}{|c|}{$\begin{array}{l}\text { *Prevalence of self reported toxicity symptoms } v \text { pesticide } \\
\text { concentration applied }\left(\chi^{2} \text { (trend) }=7.23, p=0.007\right) \text {. } \\
\text { †Prevalence of self reported toxicity symptoms } v \text { mixing pesticides } \\
\left(\chi^{2}=8, p=0.005\right) \text {. } \\
\ddagger P r e v a l e n c e \text { of self reported toxicity symptoms } v \text { re-entry period } \\
\left(\chi^{2}=0.45, p=0.79\right) .\end{array}$} \\
\hline
\end{tabular}

Farm workers were classified into three age groups: $<25$, $26-36$, and $>37$ years old. The highest self reported toxicity symptoms $(87.5 \%)$ were found in the $<25$ years old group and the lowest symptoms $(75.4 \%)$ were found in the group aged $>37$ years old. The increase in the prevalence of self reported toxicity symptoms with decrease of age was not significant $\left(\chi^{2}=4.02, p=0.13\right)$. Regarding the years of using pesticides, the increase in the prevalence of self reported toxicity symptoms with increasing periods of using pesticides was found not significant $\left(\chi_{\text {(trend) }}^{2}=1.08, \mathrm{p}=0.29\right)$.

As indicated in table 10 , the prevalence of self reported toxicity symptoms associated with pesticide exposure among farm workers was correlated with concentration of pesticides used. The prevalence of self reported toxicity symptoms among farm workers who used less, recommended, and more than recommended concentrations of pesticides was $50.0 \%$, $77.7 \%$, and $91.3 \%$, respectively. This increasing trend was found to be statistically highly significant $\left(\chi_{\text {(trend) }}^{2}=7.23\right.$, $\mathrm{p}=0.007$ ). In addition, the prevalence of self reported toxicity symptoms was higher in farm workers who mix two or more pesticides $(85.7 \%)$ than in those who do not mix them $(58.8 \%)$. Also, the increase in the prevalence of self reported toxicity symptoms as a result of mixing and not mixing pesticides was found to be highly significant $\left(\chi^{2}=8, p=0.005\right)$. The highest percentage of self reported toxicity symptoms was found among the farm workers who returned to sprayed fields within one hour of applying pesticides. The association between re-entry period and the prevalence of self reported toxicity symptoms was not significant at 2 degrees of freedom, the $5 \%$ level, and $\chi^{2}=0.45, \mathrm{p}=0.79$.

\section{DISCUSSION}

The present work was carried out in the Gaza Strip, which has several environmental problems, including concern about the effects of pesticide related activities in the agricultural sector. Pesticide problems have been identified as a major environmental health problem in the Gaza Strip. ${ }^{2-5} 1819$ The present study describes the knowledge, attitude, practice, and toxicity symptoms related to pesticide use among farm workers in the Gaza Strip.

The total response of farm workers to the questionnaire interview was relatively high, indicating good intentions to participate in the present study. The highest response was 
found in the Mid Zone Governorate while the lowest response was reported in the Rafah Governorate. This may be attributed to the employment of most farm workers in the Rafah Governorate in greenhouse work during the interview period, whereas most of those in the Mid Zone Governorate work in open fields, making them more available.

A low level of illiteracy was recorded among the respondent farm workers, reflecting a well educated community. This may give the impression that the high rate of educated farm workers is a result of them not getting another job because of the unemployment crisis in the Gaza Strip.

The percentage of the respondent farmer workers who grow their crops under greenhouses beside open fields was higher than those growing their crops in either open or closed fields. The nature of greenhouses favours the appearance of plagues, and therefore the extensive use of pesticides, which put the farm workers at high risk. ${ }^{20}$ The finding that the highest percentage of farm workers in the Gaza Strip grows vegetables will also put them at risk.

Knowledge of the respondent farm workers in the Gaza Strip about the effects of pesticides on human health was relatively accurate, a finding inconsistent with a study from the Netherlands. ${ }^{21}$ Knowledge of the names of pesticides used was also relatively accurate, whereas knowledge concerning biological and natural control was low. This necessitates the launch of educational extension programmes on pesticide alternatives among farm workers in the Gaza Strip.

The result that a high proportion of farm workers were more aware of inhalational and dermal absorption of pesticides than other routes of exposure agrees with other studies which have found that most occupational exposure to pesticides occur from skin absorption and through inhalation..$^{22}$ The present investigation showed a moderate to low awareness among farm workers towards the fate of pesticide residues in soil, in air, on plants, and in groundwater. This level of knowledge could put farm workers at risk when contact is made with pesticide residues on plants, in soil, and in dust particles after spraying.

When the respondent farm workers were questioned about their knowledge regarding pesticide associated toxicity symptoms, most knowledge was of a burning sensation in the eyes/ face, watering of eyes, cold/breathlessness/chest pain, itching/ skin irritation, headache, and dizziness. Such knowledge suggests that farm workers experienced these symptoms in situ. Most of these symptoms are considered to be common manifestations of acetylcholinesterase inhibition. ${ }^{24}$

Regarding toxicity symptoms associated with pesticides, results show that common self reported toxicity symptoms among farm workers were burning sensation in the eyes/face, dizziness, cold/breathlessness/chest pain, itching/skin irritation, and headache. These findings require urgent prevention, intervention, and protection from the Ministry of Health and other non-governmental organisations. Similar data were reported in many countries, including the neighbouring ones. ${ }^{25} 26$

The majority of the interviewed farm workers knew that wearing protective gear can protect the body from the adverse health effects of pesticides, but no one took precautions unless they knew about the measures. As concluded by the interviewer, the reason for not using protective gear, among farm workers who knew the benefit of the gear, could be attributed to carelessness, discomfort, cost, or unavailability of protective devices. The present finding is inconsistent with the study from Sri Lanka and the USA. ${ }^{27}{ }^{28}$ In this study we did not explore why awareness does not necessarily translate into action, but this point needs further investigation and could be the subject of future research.

The current investigation shows that the percentage of the interviewed farm workers who were against the use of pesticides was higher than those who agreed with pesticide use. Lack of knowledge of the other alternatives for pest control was the justification for the continuous use of pesticides. In addition, a high percentage of the interviewed farm workers believed that their bodies could develop resistance against pesticides. This is not only the attitude of farm workers in the Gaza Strip, but also the attitude of farm workers in the West Bank. ${ }^{29}$ Such attitudes may further encourage farm workers to be careless towards the use of protective measures.

Although a low percentage of the interviewed farm workers store pesticides in the home, this practice still puts children and adults at risk. In addition, the high percentage of interviewed farm workers who dispose of the empty containers on the garbage site or along the street could put the general population at risk. Such practice was considered to be one of the main problems associated with pesticide use and its management in developing countries. ${ }^{30}$

The prevalence of mixing two or more pesticides was high among the interviewed farm workers and correlated with the prevalence of self reported toxicity symptoms associated with pesticides. The synergistic effect of chemicals may contribute to this result. ${ }^{31}$ Also, the use of different concentrations of pesticides was positively associated with the prevalence of self reported toxicity symptoms among farm workers in the Gaza Strip. Use of high concentrations of pesticides is common among farm workers in the Gaza Strip. ${ }^{32}$

According to the present data the younger farm workers reported the highest self toxicity symptoms. As concluded by the interviewer, the younger farm workers often express themselves better than older ones, who sometimes hesitate to complain. Further studies are required to investigate this. A pesticide environmental extension and public awareness programme for Palestinian farm workers, which we have already started, ${ }^{33}$ will alleviate pesticide associated problems in the Gaza Strip.

\section{Authors' affiliations}

M M Yassin, Faculty of Science, The Islamic University of Gaza, Palestine

T A Abu Mourad, Environmental Protection and Research Institute-Gaza, Palestine

J M Safi, Faculty of Agriculture, Al-Azhar University, Gaza, Palestine

\section{REFERENCES}

1 Palestinian Central Bureau of Statistics. Population, housing and establishment census 1997. Palestinian National Authority, 2000.

2 Safi JM. Special problems associated with pesticides use and its management in Gaza Strip. Egyptian Journal of Occupational Medicine 1995; 19:267-76.

3 Safi JM, El-Nahhal YZ, Soliman SA, et al. Mutagenic and carcinogenic pesticides used in agricultural environment of Gaza Strip. Science of the Total Environment 1993;132:371-80.

4 Safi JM. The state of the environment in Gaza Strip. Alexandria Science Exchange 1998;19:137-50.

5 Safi JM. Association between chronic exposure to pesticides and recorded cases of human malignancy in Gaza Strip (1990-1999). The Science of the Total Environment 2002;284:75-84.

6 United States Environmental Protection Agency. U.S. EPA Methyl Bromide Phase Out. USA, 2001:12.

7 El-Sebae AH. Overview of environmental chemistry and toxicology of pesticides used in Egypt. Arab Symposium on Environment. UNSCO, University of Jordan, 1983

8 Forget G. Pesticides and third world. J Toxicol Environ Health 1991;32:11-31.

9 El-Sebae AH. Special problems experienced with pesticides use in developing countries. Regul Toxicol Pharmacol 1993;17:287-91.

10 Lopez-Carillo L, Lopez-Cervantes M. Effect of exposure to organophosphate pesticides on serum cholinesterase level. Arch Environ Health 1993:48:359-63.

11 Hogg RV, Tanis EA. Probability and statistical inference, 5th edn. New Jersey: Prentice-Hall, 1997:326-35.

12 Abu Mourad T. Hematological biomarkers of exposure in pesticide workers in Gaza Strip. Master Thesis of Public Health. Al-Quds University, Jerusalem, Palestine, 2000:22-5.

13 United States Environmental Protection Agency (USEPA). Protect yourself from pesticides: guide for pesticides handlers. USA: EPA, 1993. 
14 Clarke EK, Levy LS, Spurgeon A, et al. The problems associated with pesticide use by irrigation workers in Ghana. Occup Med 1997;47:301-8.

15 Backestrom C, Hursh-Cesar G. Survey research, 2nd edn. London, New York: Macmillan Publishing Company, Collier Macmillan Publishers, 1981:53-81.

16 Kuzma WJ. Basic statistics for the health science, 2nd edn. Mountain View, CA: Mayfiled Publishing, 1992:173-91.

17 Kirkwood BR. Essential for medical statistics. London: Blackwell Science Ltd, 1988:94-105

18 United Nation for Relief and Work Agency (UNRWA). Strategic action for development of environmental health sector in Gaza Strip. Vienna: UNRWA, 1993

19 El-Sebae AE, Safi JM. Pesticides residues and environmental pollutants as cytotoxic endocrine disrupters in human and wild life. Egyptian Journal of Occupational Medicine 1998;22:177-95.

20 Parron T, Hernandez AF, Pla A, et al. Clinical and biochemical changes in green house sprayers chronically exposed to pesticides. Hum Exp Toxicol 1996;15:957-63.

21 Meulenbelt J, de Vries I. Acute work-related poisoning by pesticides in the Netherlands: a one year follow-up study. Przegl Lek 1997;665-70.

22 Iorizzo L, Bianchi A, Gamberini G, et al. Assessment of human exposure to pesticides in greenhouses and effectiveness of personal protective devices. Arh Hig Rada Toksikol 1996;47:25-33.

23 World Health Organization. Chemical safety. 46th year. Geneva: World Health Organization, 1993:28-9.
24 Agency for Toxic Substances and Disease Registry (ATSDR). Case studies in environmental medicine: cholinesterase-inhibiting pesticide toxicity. California: Department of Health and Human Services, 1993:3-8

25 Cole DC, Carpio F, Math JJ, et al. Dermatitis in Ecuadorian farm workers. Contact Dermatitis 1997;37: 1-8.

26 Gomes J, Lloyd O, Revitt DM, et al. Morbidity among farm workers in a desert country in relation to long-term exposure to pesticides. Scand J Work Environ Health 1998;24:213-19.

27 Sivayoganathan C, Gnanachandrnn S, Lewis J, et al. Protective measure use and symptoms among agropesticide applicators in Sri Lanka. Soc Sci Med 1995;40:431-6.

28 Perry MJ, Marbell A, Layde PM. Association of pesticide safety knowledge with beliefs and intentions among farm pesticide application. J Occup Environ Med 2000;42: 187-93.

29 Saleh A, Neiroukh F, Ayyash O, et al. Pesticides usage in the West Bank. Palestine: Applied Research Institute, Jerusalem, 1995:17.

30 Wesseling C, McConnell R, Partanen T, et al. Agricultural pesticide use in developing countries: health effects and research needs. Int J Health Serv 1997;27:273-308.

31 Allaby M. The concise oxford dictionary of ecology. Oxford: Oxford University Press, 1994:378.

32 Abu Middain R. Evaluation of agriculture pesticides use in the Gaza Strip. Dissertation for Master of Public Health. College of Medicine, University of Wales, UK, 1994:14-15.

33 Safi JM, El-Nahhal YZ, Kaware MG, et al. Initiation of a pesticide environmental extension and public awareness program for Palestinian community in Gaza Strip. J Pest Control Environ Sci 2000;8:75-98.

OEM web submission and review system

I am pleased to inform authors and reviewers of the new online submission and review system at OEM. Developed by Highwire Press (CA, USA), Bench>Press is a fully integrated electronic system which uses the internet to allow rapid and efficient submission of manuscripts. It also allows the peer review process to be conducted entirely online. The main aim is to speed up the frequently frustrating progress from submission to publication.

Authors can submit their manuscript in any standard word processing software. Standard graphic formats acceptaed include: .jpg, .tiff, .gif, eps, etc. (Please note: multi page powerpoint files are not accepted by the BM Publishing Group.) The text and graphic files are automatically converted to PDF for ease of distribution and reviewing purposes. Authors are asked to approve their submission before it formally enters the reviewing process. On approval, the submission is passed to the editor and/or reviewers via the web. All transactions are secure.

To access the system click on "SUBMIT YOUR MANUSCRIPT HERE" on the OEM homepage: http://www.occenvmed.com, or you can access the submission site directly at http://submitoem.bmijournals.com.

We are very excited with this new development and would encourage authors and reviewers to use the system where possible. It really is simple to use and should greatly improve on the current peer review process. Full instructions can be found on Bench>Press http://submitoem.bmijournals.com and OEM online at http://www.occenvmed.com. Please contact Natalie Davies, Project Manager, ndavies@bmigroup.com.

Anne Cockcroft

Editor, OEM 


\section{LETTERS}

\section{Neurobehavioural testing in workers occupationally exposed to lead}

Whether or not low to modest levels of exposure to lead have a detrimental effect on cognition is an important issue given the growing attention, for example, in the United States, that has recently been paid towards potentially revising downward the levels of lead exposure allowed in the workplace. Thus, we read with interest the meta-analysis of studies on this topic that appeared in this journal by Goodman and colleagues. ${ }^{1}$ Unfortunately, we believe that the authors' conclusions are not valid. Specifically, the authors state that "the data available to date are inconsistent and are unable to provide adequate information on the neurobehavioural effects of exposure to moderate blood concentrations of lead". We found no direct support for this conclusion in the publication. Moreover, numerous flaws in their method limit any specific inferences that can be made. In general, we found that the meta-analysis combined evidence from studies of widely varying quality and did not account for significant confounding within and between studies. Given these and othe flaws, it was predictable that the authors did not find an association between blood lead levels and neurobehavioural test scores.

Specific concerns that we had with the methods include: (1) The authors offer no evaluation of the quality of the evidence from available studies based on study design and analytical method. (2) The authors combine data from poorly done studies with data from well done studies, clouding any effects that are observable from the better conducted studies. (3) Although age and education adjustment within studies is assessed, six studies were included that did not adjust for age, and another three studies did not adjust for education. These are the two most well established predictors of neurobehavioural test scores and the most important potentially confounding variables. (4) Even among the remaining studies that did adjust for age and education, the authors do not address the confounding in the meta-analysis that is caused by variation in age and education across study populations. (5) The authors' main effect measure is an exposed versus control comparison. Among the options that could have been pursued, this is the effect measure with the lowest power. It is unable to assess a dose-effect relation, and it is also the one most prone to selection bias. (6) Relatively few of the 22 studies listed in table 2 contribute to the estimate of the effect size for each neurobehavioural outcome. Moreover, the authors do not state which studies contributed to the effect estimate.

It is important to note that several recent studies, all published before this article was accepted for publication, reported that blood lead was associated with neurobehavioural test scores in multiple cognitive domains. One study of 803 Korean lead workers is the largest study reported to date and observed consistent associations of blood lead with tes scores in the domains of executive abilities,
If you have a burning desire to respond to a paper published in Occupational and Environmental Medicine, why not make use of our "rapid response" option?

Log on to our website (www.occenvmed.com), find the paper that interests you, and send your response via email by clicking on the "eletters" option in the box at the top right hand corner.

Providing it isn't libellous or obscene, it will be posted within seven days. You can retrieve it by clicking on "read eletters" on our homepage.

The editors will decide as before whether to also publish it in a future paper issue.

manual dexterity, and peripheral motor strength at blood lead levels as low as 18 $\mathrm{\mu g} / \mathrm{dl}{ }^{2}$ In another study of former organolead manufacturing workers, tibia lead was associated with test scores at cross section and with longitudinal declines in test scores. ${ }^{3}$ These findings suggest that lead may have both short term and progressive influences on neurobehavioural performance.

We elaborate on our main concerns, below.

(1) No evaluation of the quality of the evidence available from studies, and (2) Data from poorly done studies were combined with data from well done studies. It is traditional in meta-analysis to establish a priori criteria for what defines acceptable evidence from studies. The authors only had three inclusion criteria, none of which refer to the quality of the study designs, analytical method, adjustment for confounding, evaluation of bias in selection of exposed and non-exposed subjects, and other such methodological factors. There is apparently no consideration for this arguably single most important step in metaanalysis. The meta-analytical results could simply reflect wide heterogeneity in the quality of the evidence that was combined. This factor alone could account for the overall conclusion of no association.

(3) Inclusion of studies that did not control for age and education. Age and education are the two most important predictors of neurobehavioural test scores in working populations. In the absence of adjustment for these confounders there should be convincing evidence that the two groups being compared were equivalent in age and education. Eight of the included studies did not adjust for age and/or education. The authors offer no explanation for why these studies should be included in the meta-analysis.

(4) No adjustment for age, education, or lead dose differences across studies. By not adjusting for age and education differences across studies, the authors make an implicit assumption that age and education do not modify the relation between blood lead and neurobehavioural test scores. This may or may not be true. In the meta-analysis, the authors also implicitly assume a fixed difference in blood lead levels between exposed and nonexposed groups. Table 1 clearly indicates that this assumption does not hold

(5) Reliance on exposed versus control comparisons. This is a weak test and a test that is not germane to the conclusions that the authors make. The authors conclude that blood lead levels, that are described as "moderate" in one location in the manuscript and "low" in another, are not associated with neurobehavioural test scores. All studies included exposed workers with a range of blood lead levels, from very low to high. More appropriate approaches could have been considered, for example, only including studies that reported beta coefficients for the blood lead versus test score relation, or adjusting for mean blood lead levels in exposed and non-exposed groups.

(6) Reliance on a small number of unspecified studies for effect estimates. Table 2 of the meta-analysis reports the number of studies that were combined to derive effect estimates, but does not specify which studies were combined. This omission does not allow the reader to determine whether solid evidence was combined with more questionable evidence, or to evaluate whether any of the issues described above were germane to the effect estimates reported.

Two more concerns exist regarding the authors' treatment of the issue of cumulative versus ongoing lead exposure, as well as the identification of the source of funding for this study. In their introduction, the authors quote the review by Balbus-Kornfeld et al, which noted that "the current scientific evidence is flawed because of inadequate estimation of cumulative exposure to or absorption of lead

"." but fail to acknowledge this issue in the interpretation of their own meta-analysis. In fact, as has been widely reported in the literature, methods are now available to noninvasively measure bone lead levels as a reliable and accurate measure of cumulative lead dose. Several studies ${ }^{3-5}$ suggest that cumulative lead dose, as measured by tibia lead levels, is a very important biological marker that may be related to cognitive decrements not predicted by blood lead levels. With regard to funding, the authors note that they are mainly from the Exponent Health Group in Alexandria, Virginia, and Menlo Park, California; however, they fail to describe what motivated the study or sources of funding for the study. We believe this information would be of interest to scientists and policy makers engaged in work on this topic.

B S Schwartz

Professor and Director, Division of Occupational and Environmental Health, Johns Hopkins Bloomberg School of Public Health: bschwart@jhsph.edu

W Stewart

Adjunct Professor, Department of Epidemiology, Johns Hopkins Bloomberg School of Public Health

$\mathrm{H} \mathrm{Hu}$ Associate Professor and Director Occupational/Environmental Medicine, Department of Environmental Health, Harvard School of

Public Health

\section{References}

1 Goodman M, LaVerda N, Clarke C, et al. Neurobehavioural testing in workers occupationally exposed to lead: systematic review and meta-analysis of publications. Occup Environ Med 2002;59:217-23. 
2 Schwartz BS, Lee BK, Lee GS, et al. Associations of blood lead, dimercaptosuccinic acid-chelatable lead, and tibia lead with neurobehavioral test scores in South Korean lead workers. Am J Epidemiol 2001;153:453-64.

3 Stewart WF, Schwartz BS, Simon D, et al. Neurobehavioral function and tibial and chelatable lead levels in 543 former organolead workers. Neurology 1999;52:1610-17

4 Schwartz BS, Stewart WF, Bolla KI, et al. Past adult lead exposure is associated with longitudinal decline in cognitive function. Neurology 2000;55: 1 144-50.

5 Payton M, Riggs KM, Spiro A III, et al. Relations of bone and blood lead to cognitive function: the VA Normative Aging Study. Neurotox Teratol 1998;20:19-27.

\section{Suicide mortality among electricians}

Järvholm and Stenberg ${ }^{1}$ evaluated suicide mortality rates among electricians ("exposed to electromagnetic fields (EMFs)") and glass and wood workers ("unexposed to EMFs") in the Swedish construction industry. Standard mortality rates were lower for the two job groups compared to the Swedish general population. This is likely to be due to the healthy worker effect. The internal cohort analysis showed that electricians had a lower suicide mortality rate than glass and wood workers.

As the authors rightfully point out, these results should not be seen as evidence against the association between exposure to EMFs and suicide, in particular because no quantita tive estimates of exposure were obtained to directly evaluate this association. Järvholm and Stenberg cited a small measurement sur vey in the Swedish construction industry, which indicated that exposure levels were low and comparable between the two occupational groups. Therefore, one would not expect to see an EMF mediated increase in suicide risk among electricians compared to glass and wood workers, if an association between EMF exposure and suicide truly exists.

Järvholm and Stenberg suggested that the difference in suicide rate between the two job groups was unlikely to be due to differences in socioeconomic factors, but they did not provide an alternative explanation. One possible explanation may be a healthy worker survivor effect related to employment status (for example, at time of death) within this cohort That is, active workers may be more physically and mentally fit than those who left the industry or are unemployed, and may therefore be at lower risk of committing suicide. ${ }^{2} \mathrm{~A}$ large body of literature suggests that unemployment and suicide are positively related, ${ }^{3}$ and being out of work was positively associated with suicide in the electric utility industry. ${ }^{2}$ Since cessation of work also leads to cessation of work related exposures, employment status may be an important potential confounder (or perhaps effect modifier) for the association between work related exposures and suicide. The lower suicide rate among electricians compared to glass and wood workers may be explained by a larger proportion of glass and wood workers with an inactive employment status at the time of death.

Although it is unlikely that consideration of employment status, if possible, would greatly alter the conclusions reached by Järvholm and Stenberg, ${ }^{1}$ it would be informative to see its influence on the rate ratio.

E van Wijngaarden Department of Epidemiology, School of Public Health, University of North Carolina at Chapel Hill, Chapel Hill, NC 27599-7435, USA edwin@unc.edu

\section{References}

1 Jarvholm B, Stenberg A. Suicide mortality among electricians in the Swedish construction industry. Occup Environ Med 2002; 59: 199-200.

2 van Wijngaarden E, Savitz DA, Kleckner RC, et al. Exposure to electromagnetic fields and suicide among electric utility workers: a nested case-control study. Occup Environ Med 2000;57:258-63.

3 Dooley D, Fielding J, Levi L. Health and unemployment. Annu Rev Public Health 1996;17:449-65

4 Kposowa AJ. Suicide mortality in the United States: differentials by industrial and occupational groups. Am J Ind Med 1999;36:645-52

\section{Authors' reply}

We appreciate Dr Wijngaarden's interest in our report and his suggestion for understanding the differences in risk. Dr Wijngaarden suggests that difference in unemployment rate between electricians and glass worker and wood workers could be an explanation.

We have no data on employment status at time of death and can therefore not test this hypothesis. However, if employment status is an important predictor, this could explain some of the difference, as the wood workers had a different employment structure to the other groups. Electricians and glass workers have had permanent positions for a long time, while wood workers were employed for a certain project, for example, building a house, before the 1990s. When the project was finished they had to find another employer. Today, most construction workers have permanent positions in Sweden.

In our search of the literature in an attemp to understand differences in suicide rates between occupations, we found little information. This might be an important area of research in the future.

B Jarvholm, A Stenberg

Dept of Public Health and Clinical Medicine Occupational Medicine, Umeå University, S-901 87 Umeå, Sweden bengt.jarvholm@envmed.umu.se

\section{Are incinerator workers exposed to PCDDs and PCDFs?}

Kumagai and his colleagues ${ }^{1}$ have reported that incinerator workers employed at intermittently burning incineration plants were not necessarily exposed to high concentrations of polychlorinated dibenzo- $p$-dioxins (PCDDs) and polychlorinated dibenzofurans (PCDFs). The authors' conclusions were based on concentrations of PCDDs and PCDFs in serum samples of the workers.

I have deep concerns regarding the study methodology and results which do not consider the accumulation of PCDDs and PCDFs in the adipose tissue. PCDDs and PCDFs are organochlorines with different degrees and positions of chlorination, which determine their persistence and toxicity. They are lipophilic and difficult to metabolise, and any environmental exposure of living organisms to them results in their accumulation and persistence in fat tissues. ${ }^{2}$ Meanwhile, it is feasible to use blood sera to obtain and analyse PCDDs and PCDFs. Adipose tissue organochlorines levels have been regarded as a preferred indicator of human exposure. Levels in adipose tissue are known to be higher and more representative of the cumulative internal exposure. ${ }^{23}$ Previously, ArchibequeEngle and colleagues ${ }^{4}$ did not find a significant relation between serum concentration and tissue residues for organochlorine compounds. Based on the lack of correlation between adipose tissue and serum, as well as an absence of some compound residues in serum, the authors emphasised that adipose tissue should be analysed in addition to serum

Finally, I would like to acknowledge the authors for such original subject study, which enables us to raise the profile of and discuss new hypotheses in environmental and occupational health.

Department of Preventive Medicine and Public Health, University of Cordoba, Spain:

fm2faahm@uco.es

\section{References}

1 Kumagai S, Koda S, Miyakita T, et al. Polychlorinated dibenzo-p-dioxin and dibenzofuran concentrations in serum samples of workers at intermittently burning municipal waste incinerators in Japan. Occup Environ Med 2002;59:362-8.

2 Angulo R, Martinez P, Jodral ML. PCB congeners transferred by human milk, with an estimate of their daily intake. Food Chem Toxicol 1999;37:1 1081-8

3 Lopez-Carrillo L, Torres-Sanchez L, Lopez-Cervantes $M$, et al. The adipose tissue to serum dichlorodiphenyldichloroethane (DDE) ratio: some methodological considerations. Environ Res 1999;81:142-5.

4 Archibeque-Engle SL, Tessari JD, Winn DT, et al. Comparison of organochlorine pesticide and polychlorinated biphenyl residues in human breast adipose tissue and serum. J Toxicol Environ Health 1997;52:285-93.

\section{Importance of work intensity on respiratory problems in hairdressers}

We read the report by Hollund et al with great interest. ${ }^{1}$ We agree that there is limited information about the prevalence of airway symptoms caused by highly reactive chemicals in hairdressing salons. In this well designed study, authors focused on age as a risk factor and observed an increased prevalence of respiratory symptoms among the oldest and youngest hairdressers and observed more symptoms among hairdressers over 40 years of age.

Work intensity, work duration, working conditions, and job titles (master, and fellow hairdresser) should also be considered as risk factors for occupational asthma and respiratory symptoms. With the exception of work intensity, these features have been reported as risk factors in previous studies. ${ }^{2-4}$ Work intensity is an objective parameter for evaluating occupational exposures. In our study, we calculated work intensity from the average number of chemical applications per week (bleaching, dye, and permanent wave) and observed a 3.6 times higher risk of occupational asthma among hairdressers with high work intensity (95\% CI 1.2 to 10.9 ) with a significant trend $\left(\chi_{\text {trend }}^{2} 4.9, \mathrm{p}=0.027\right) .{ }^{5}$ However, we did not observe any excess by work duration, which probably is a result of the healthy worker effect. Hollund et al stated that the older hairdressers had more customers than the younger ones, which may be 
evidence of higher occupational exposures. If they had used work intensity as a more objective criterion than age, they might have prevented possible misclassifications by age. Working conditions of hairdressers and exposures depend on country and regional variability, which might also affect study results. In the United States and United Kingdom, the term "hairdressers" is inclusive, denoting women's hairdressers and barbers for men. ${ }^{6}$ In Turkey, however, the term addresses women's hair salons only. Most of the studies on hairdressers have been published from Nordic and industrialised countries. ${ }^{7-11}$ Studies from developing countries will help to describe the extent of occupational health problems among hairdressers and to identify aetiological factors.

M Akpinar-Elci, O C Elci

National Institute for Occupational Safety and Health, DRDS/FSB MS2800 1095 Willowdale Road, Morgantown, WV 26505, USA; mra8@cdc.gov

\section{References}

1 Hollund $\mathrm{BE}$, Moen $\mathrm{BE}$, Lygre $\mathrm{SH}$, et al. Prevalence of airway symptoms among hairdressers in Bergen, Norway. Occup Environ Med 2001:58:780-5.

2 Blainey AD, Ollier S, Cundell D, et al. Occupational asthma in a hairdressing salon. Thorax 1986;41:42-50.

3 Parra FM, Igea JM, Quirce S, et al. Occupational asthma in a hairdresser caused by persulphate salts. Allergy 1992:47:656-60.

4 Schwaiblmair M, Vogelmeier C, Fruhmann $G$. Occupational asthma in hairdressers: results of inhalation tests with bleaching powder. Int Arch Occup Environ Health 1997.70:419-23.

5 Akpinar-Elci $\mathbf{M}$, Cimrin AH, Elci OC Prevalence and risk factors of occupational asthma among hairdressers in Turkey. J Occup Environ Med 2002. In press.

6 Occupational exposures of hairdressers and barbers and personal use of hair colorants; some hair dyes, cosmetic colorants, industrial dyestuffs and aromatic amines. IARC monographs on evaluation of carcinogenic risks to human 1993;57:43-66.

7 Leino T, Tammilehto L, Luukkonen R, et al. Self-reported respiratory symptoms and diseases among hairdressers. Occup Environ Med 1997:54:452-5.

8 Leino T, Tammilehto L, Paakkulainen $\mathrm{H}$, et al. Occurrence of asthma and chronic bronchitis among female hairdressers. A questionnaire study. J Occup Environ Med 1997;39:534-9.

9 Leino T, Tammilehto L, Hytonen M et al. Occupational skin and respiratory diseases among hairdressers. Scand J Work Environ Health 1998;24:398-406.
10 Leino $\mathrm{T}$, Tuomi $\mathrm{K}$, Paakkulainen $\mathrm{H}$, et al. Health reasons for leaving the profession as determined among Finnish hairdressers in 1980-1995. Int Arch Occup Environ Health 1999;72:56-9.

11 Hollund BE, Moen BE. Chemical exposure in hairdresser salons: effect of local exhaust ventilation. Ann Occup Hyg

1998:42:277-82

\section{NOTICES}

27th International Congress on

Occupational Health: The

Challenge of Equity in Safety

and Health at Work, Iguassu

Falls, Brazil, 23-28 February

\section{3}

The Congress will have about nine keynote conferences, approaching different angles of the Central Theme; those themes will then be discussed in depth by Panels (60), where different opinions will be debated. There will be about 60 mini-symposia organised by the $\mathrm{ICOH}$ Scientific Committees and Work Groups; facilities for the presentation of 1000 posters; and about 500 free papers. Interest groups may schedule meetings in Congress areas.

Conference Secretariat

Tel/Fax: (5541) 3536719

Email: icoh2003@com.br

Website: www.icoh2003.com.br

\section{First World Congress on}

Work-Related and

Environmental Allergy (1st

WOREAL), and Fourth

International Symposium on

Irritant Contact Dermatitis (ICD), Helsinki, Finland, 9-12 July

2003

Congress on Work-Related and

Environmental Allergy

- Work related and environmental aspects of respiratory and skin allergy

- Specific issues related to pathophysiology and skin allergy
- Management and prevention of allergy Irritant Contact Dermatitis Symposium

- Occupational irritant dermatitis

- Prevention of irritant dermatitis

- Alternative methods for the assessment of irritants

- Irritant dermatitis from cosmetics

Satellite events

- Satellite Symposia, 9 July 2003

- Allergy School, 9-10 July 2003

- 7th International NIVA Course on WorkRelated Respiratory Hypersensitivity, 11-15 July 2003

Congress Secretariat

Ms Kirsi Saarelma, Congress Manager

Pyykkö \& Saarelma Ltd

Limingantie 9

FIN-00550 Helsinki, Finland

Tel: +3589790080

Fax: +35897573630

Email: secretariat@woreal.org

Website: www.woreal.org

\section{CORRECTIONS}

We apologise for the following errors in table 4 of the paper by Wong et al (Associations between daily mortalities from respiratory and cardiovascular diseases and air pollution in Hong Kong, China. Occup Environ Med 2002;59:30-5).

- Mortality from pneumonia and influenza: 4 Pollutant model, under $\mathrm{NO}_{2}$ : "l.004 (1.017 to 1.025$)$ " should read: "1.004 $(0.984 \text { to } 1.025)^{\prime \prime}$.

- Mortality from ischaemic heart diseases 2 Pollutant model, also under $\mathrm{NO}_{2}$ : “1.022

(1.011 to 1.003$) "$ should read: "1.022 (1.011 to 1.033$)^{\prime \prime}$.

We apologise for the following error in the paper by Yassin et al (Knowledge, attitude, practice, and toxicity symptoms associated with pesticide use among farm workers in the Gaza Strip. Occup Environ Med 2002;59:387393).

The page reference at the start of the paper should be 387-393, and not 387-394. 